\title{
DISCURSOS SOBRE DEL CENTENARIO DE LA CAMPAÑA NACIONAL DE 1856
}

\section{SPEECHES ABOUT THE 100TH ANNIVERSARY OF THE NATIONAL CAMPAIGN OF 1856}

\section{Chester Urbina Gaitán*}

\author{
RESUMEN
}

Algunos de los discursos emitidos en el centenario de la Campaña Nacional de 1856, fueron enfocados en la importancia de este hecho, en la integración centroamericana y hemisférica con Estados Unidos. Se dejó por sentada la existencia de Juan Santamaría y se exaltó la actitud visionaria de Juan Rafael Mora Porras en la conducción del enfrentamiento contra los filibusteros, consolidando un discurso conservador y patriarcal de la historia nacional.

PALABRAS CLAVE: COSTA RICA * CAMPAÑA NACIONAL * $1956 *$ NACIONALISMO * ESTADO

* IGLESIA * PRENSA

\section{ABSTRACT}

Some of the speeches issued on the 100th anniversary of the National Campaign of 1856 focused on the importance of this fact in the central American integration and hemispheric with the United States. It was left for granted the existence of Juan Santamaria and exalted the foresight of Juan Rafael Mora Porras in the conduct of the confrontation against the filibuster by consolidating a speech conservative and patriarchal of national history.

KEYWORDS: COSTA RICA * NATIONAL CAMPAIGN * $1956 *$ NATIONALISM * STATE * CHURCH * PRESS

Instituto de Estudios Latinoamericanos de la Universidad Nacional de Costa Rica.

chesterurbina@yahoo.com 


\section{INTRODUCCIÓN}

Para el historiador Raúl Aguilar, la celebración del Centenario de la Campaña Nacional constituye el punto máximo de interés sobre el tema de la guerra contra los filibusteros a nivel historiográfico. En el marco de este festejo aparecen publicados los dos únicos libros que en el siglo XX son resultado de investigaciones históricas científicas.

Armando Rodríguez Porras en su investigación: Juan Rafael Mora y la guerra contra los filibusteros, se concentra en los antecedentes $y$ lo que usualmente se conoce en el medio costarricense como la primera etapa de esta guerra o primera campaña. El otro libro es el de don Rafael Obregón Loría: La Campaña del Tránsito, donde se acota la importancia de los acontecimientos sucedidos durante la segunda campaña, hasta ese entonces tratada sin valorar la importancia estratégica, decisiva y determinante que tuvieron estos hechos en la guerra contra los filibusteros.

El Partido Comunista de Costa Rica participó en los actos conmemorativos del Centenario de la Campaña Nacional, con la publicación de un libro: Los Estados Unidos y la Campaña Nacional 1856-1857: acusación ante la Historia, que sin pretender apoyarse en fuentes primarias ni brindar nuevos aportes al conocimiento del tema, aclara su posición ideológica en la lucha antiimperialista. Asimismo, se realizaron pequeñas publicaciones con la reproducción de trabajos testimoniales que originalmente fueron publicados en los periódicos del país.

Con la celebración del Centenario de la Campaña Nacional y en los años siguientes, la Revista de los Archivos Nacionales, dio a conocer trabajos monográficos en números específicos o por entregas sobre el tema del filibusterismo, o bien, traducciones al español de obras de autores estadounidenses (En: <http://www. latindex.ucr.ac.cr/historia-51/10-Aguilar.pdf $>$ ). También sobresalen los trabajos de Carlos Meléndez (1979, 1982 y 1983), Eugenia Ibarra (1992) y Rafael Méndez (2007). En el libro: La Campaña Nacional (1856-1857): historiografía, literatura y memoria, se realiza un balance de las diferentes investigaciones $y$ obras literarias sobre este hecho histórico, incluidas las realizadas durante el centenario, donde se resalta la contraposición de una interpretación antiimperialista de derecha con una de izquierda en torno a la campaña (Molina y Díaz, 2008: 34).

Este artículo tiene como objetivo abordar una parte de la historia sobre la memoria de la Campaña Nacional de 1856, al explorar algunas de las posiciones e interpretaciones que se vertieron en la prensa nacional con respecto al centenario de esta gesta heroica, principalmente en torno a la consagración del heroísmo de Juan Santamaría y del ex presidente de la República Juan Rafael Mora Porras.

GESTA HEMISFÉRICA, HEROÍSMO EJEMPLARIZANTE Y RESCATE DEL MÁRTIR: LAS VALORACIONES SOBRE EL CENTENARIO DE LA CAMPAÑA NACIONAL DE 1856

El martes 10 de abril de 1956, el periódico La Nación publicó el discurso pronunciado por el entonces presidente José Figures Ferrer en el homenaje al General José María Cañas, al iniciarse en San José los festejos del Centenario del 56. El ex presidente José Figueres comienza señalando que la campaña de 1856 tenía más importancia americana de la que se le había dado en la historia. Tenía importancia en el campo de América Central y en el ámbito de las relaciones hemisféricas.

Acota que la victoria sobre William Walker fue a la vez el triunfo contra ciertos errores centroamericanos y contra equivocadas políticas que existieron entre Estados Unidos y América Latina. Además, indica que siempre han existido en los cinco países centroamericanos, divisiones internas que han debilitado el esfuerzo común, ante los filibusteros de hace un siglo o ante cualquier otro peligro de ayer o de esta época.

Para el ex mandatario, en la guerra del 56, nuestros abuelos campesinos pusieron término, en un mismo golpe, a las rivalidades internas que conducían hasta la alianza con el invasor y a la conquista del viejo imperio español que es América Latina, por filibusteros del norte. Así también, Costa Rica, la tradicional amiga de los Estados Unidos, salió a detener a los hijos descarriados de la potencia continental. 
Según el ex gobernante, uno de los signos de los nuevos tiempos era la integración económica del istmo, que caminaba rápidamente, ayudada por la Comisión Económica para América Latina y el Caribe (CEPAL), la Organización de Estados de Centroamérica (ODECA), las frecuentes conferencias de ministros y funcionarios de los países de la región, para la solución de problemas comunes y la construcción de la carretera Interamericana, gran obra material de aliento unionista.

En el campo hemisférico sobresalían los programas de asistencia técnica llamados del Punto Cuarto; el robustecimiento de la Organización de los Estados Americanos (OEA) y el avance hacia la estabilidad del mercado internacional por medio de los organismos multinacionales como el Banco Mundial y el Fondo Monetario Internacional. Termina el ex presidente Figueres Ferrer proclamando que se marchaba hacia un hemisferio americano espiritualmente unido por la igualdad de derechos y de niveles de vida ( $L a$ Nación, 1956: 12).

La celebración del Centenario de la Campaña Nacional para Figueres se localiza en su visión, de que el desenvolvimiento de América Latina en las áreas económica, social, cultural y política, solo se podía llevar a cabo en la conformación de una civilización hemisférica junto a Estados Unidos. Un desenvolvimiento hemisférico general implicaba, para América Latina, la aceptación, o más bien, la demanda de la dirección ejercida por los Estados Unidos. Suponía también la determinación, por parte de los Estados Unidos, de ejercer tal dirección, con arreglo a la línea de conducta democrática "occidental" (En:<http://www.editorialpln. info/publicaciones/Escritos_de_Jose_Figueres_ Ferrer.pdf.> Pp.381-382).

El interés de Figures de mantener la armonía con Estados Unidos se encuentra inmerso en el contexto de la Guerra Fría y de unión a la potencia hemisférica. Con respecto a la celebración del centenario de la batalla de Santa Rosa, el líder político acota que Santa Rosa, tumba de filibusteros, no es para nosotros campo donde se cultive la animosidad hacia los Estados Unidos. Ni el Gobierno, ni el pueblo norteamericano aprobaron la aventura de
Walker y sus hombres. Al contrario, la censuraron categóricamente e hicieron lo posible por evitar el enganche de nuevos voluntarios (ibid. p.151).

Con respecto al contexto en el cual se emite este discurso, Alfonso González ha señalado como el movimiento anticomunista se articula y consolida a lo largo de toda la década de 1950. Desde las instituciones del gobierno y desde la prensa escrita se despliega una guerra psicológica, cuyo propósito manifiesto es fortalecer entre la población en general, reacciones de evitación $y$ distanciamiento respecto al comunismo, sus ideas y seguidores (2005: 20).

Para el 11 de abril de 1956 en la ciudad de Alajuela, el Lic. Jorge Rossi Ch. Ministro de Economía y Hacienda, encargado del despacho de Educación Pública, pronunció el discurso oficial a la memoria del soldado Juan Santamaría. El Ministro resalta que el fervor cívico con que todos los costarricenses se habían congregado en derredor del Monumento a Juan Santamaría, significaba que el sistema educativo asumió, desde hacía mucho tiempo, la misión de mantener el culto permanente a los héroes de la Campaña Nacional de 1856 y 1857.

Además, apunta que las aulas de escuelas de Costa Rica, han sido templos donde cientos $y$ miles de estudiantes, han aprendido a venerar la memoria de Juan Santamaría, con la de Juan Rafael Mora y la de José María Cañas. Para el funcionario público, un ejército solo puede lograr tanto heroísmo como el de las tropas costarricenses, cuando se tienen llenos los arsenales de la virtud hogareña, de la abnegación femenina y de la unción religiosa (La Nación, 1956: 3 y Díaz, 2006: 37-56).

El discurso de Rossi posee un fuerte contenido moralizador, cuya intención era la de mantener el control ideológico sobre los grupos subalternos. Hacia finales del siglo XIX se fue construyendo un "discurso nacional" a través de la literatura, en donde la nación costarricense también se creó. Así, hasta principios del siglo $\mathrm{XX}$, se presenta una visión de la sociedad costarricense que legitima el discurso oficial y que reduce a Costa Rica al Valle Central y coloca al campesino, el "concho", como el héroe costarricense cotidiano y al mundo rural, como 
la representación de la Costa Rica pasiva e ideal (En: <http://bibliotecavirtual.clacso.org.ar/ar/ libros/becas/2000/diaz.pdf> P.4).

Los valores que deben mantener unida a la comunidad nacional descansan sobre el arquetipo del campesino mítico, que hace de las virtudes privadas el fundamento exclusivo del orden social. La interpelación nacionalista que vehiculiza, no pretende constituir ciudadanos críticos y participativos, sino esposos e hijos bondadosos dispuestos a sacrificarse por la familia $y$ por la patria (Villena, 2006: 169). Uno de los principales medios utilizados por el Estado costarricense para transmitir este discurso de inculcamiento de valores, sistemas de valores $y$ comportamientos tradicionales es por medio de la escuela. La invención de tradiciones es un proceso de formalización y ritualización, cuya característica es la adaptación de viejas costumbres, tradiciones e imaginarios a nuevas condiciones y propósitos. A través de ese proceso se crean $y$ reproducen ciertos valores y normas de comportamiento por repetición impuesta, que automáticamente implican continuidad con el pasado (Hobsbawn y Ranger, 2002: 16).

En el momento en que el Lic. Rossi emite su discurso, el consumo femenino se orientaba a los productos de uso personal y doméstico. Con la inserción activa de la mujer en la esfera del consumo, se esperaba beneficiar el crecimiento industrial y económico de la sociedad (González, 2005:165-166).

Otra posición que se emitió sobre la guerra contra los filibusteros, fue la de historiadores que escribieron en el periódico religioso Eco Católico. Don Ricardo Blanco Segura refuerza la existencia de Juan Santamaría, al subrayar que este era una realidad histórica comprobada, un soldado de carne y hueso, que vivió, peleó y derramó su sangre heroica por la patria en una acción inolvidable. No podía ser de otro modo. Eran muchos los argumentos y las pruebas que en su favor existían: los documentos, los testigos y la tradición. Eran pocos, débiles y escasos, los posibles argumentos en contra, los cuales ya habían sido totalmente aniquilados por la crítica sana y concienzuda (Eco Católico, 1956: 297).

Asimismo, agrega que además de ser nuestro héroe, Juan Santamaría es también nuestro símbolo más hermoso, que es la modestia. Representó la forma más limpia y más pura de amor a la patria (ibid. p.298).

Pese al interés de Blanco Segura por dejar sentada la existencia de Santamaría, no entra a valorar las pruebas que existían a favor o en contra de la vida del héroe nacional. La posición de la iglesia hasta ese momento cuestionaba la existencia de Juan Santamaría, la cual quedó plasmada en una publicación de Monseñor Víctor Manuel Sanabria de 1932, donde se rechaza que Santamaría hubiera estado en la batalla de Rivas, ya que este había muerto de cólera en el camino de Nicaragua a Costa Rica (1932). Para Iván Molina existen pruebas documentales escritas — como la solicitud de pensión de la madre de Santamaría en 1857, el discurso de José de Obaldía de 1864 y la información levantada por la Secretaria de Guerra en 1891- que confirman que Juan Santamaría existió, que estuvo presente en la batalla de Rivas, que fue uno, entre otros, de los que participaron en la quema del mesón y que falleció en el cumplimiento de esa tarea (2006: 9 y 2000).

Por su parte, Francisco María Núñez, Presidente de la Academia Costarricense de la Historia, refiere que indudablemente la voz de Monseñor Anselmo Llorente y Lafuente, contribuyó a fervorizar a los humildes soldados del 56 (Eco Católico, 1956: 298). Sin las virtudes, del pueblo costarricense -laboriosidad, culto al hogar, catolicismo práctico y civismo ejemplar- la Guerra de 1856 y 1857 no se habría ganado (ibid. p.299).

Según Núñez, para unos Juan Santamaría era el símbolo del soldado desconocido; para el resto de costarricenses, era la representación humana, real de nuestros humildes labriegos $y$ artesanos, que a la hora sublime de los renunciamientos, se transfiguran en héroes, en defensa de sus más caros afectos: la patria, la familia, el pedazo de tierra de labranza y los animalillos, compañeros amables de la vida.

El párrafo anterior es interesante, pues continúa con el discurso liberal sobre la figura de Santamaría. Según Palmer, Juan Santamaría es un héroe de origen popular, de 
las clases populares. Casi todo el esfuerzo de los publicistas liberales de finales de la década de 1880 y principios del decenio de 1890, estuvo dirigido a subrayar la posición de clase de Santamaría. Ni siquiera era un campesino o agricultor independiente, pertenecía a los sectores más humildes de la época en que le tocó vivir, era un sencillo trabajador (Molina, 2007: 124).

Don Francisco continúa su relato aclarando que Costa Rica fue a defender a los hermanos de Nicaragua. Así, un pueblo de "hermaniticos" sencillos, trocó las herramientas de labranza por el viejo y herrumbrado "fusil de chispa" - por falta de uso, casi inservible-y que se convirtió en arma vengadora, por el desprendimiento y el coraje de quienes lo dirigieron, en defensa de la sacro santa religión, del amado hogar, de la familia idolatrada, en suma de la patria, conjunción de todos los amores (Eco Católico, 1956: 299).

El discurso de Núñez resalta el aspecto conservador de Juan Santamaría, ya que este ofrendó su vida en territorio extranjero para conservar el orden establecido en Costa Rica. El mito de Santamaría no es de liberación nacional, sino de preservación nacional, la preservación de instituciones liberales, de una religión $y$ de la jerarquía social prevaleciente (Molina, 2007: 124-125).

Otra posición que hubo sobre el centenario de la gesta contra los filibusteros, se dio en el periódico de Quepos denominado Lucha. Para el 7 de julio de 1956 don Carlos Ortega Castillo, secretario de la municipalidad del cantón antes citado, publicó una serie de artículos sobre el aniversario de la Campaña Nacional titulados: "LAUdE: Evocación de Mora. El hombre; el estadista; el héroe; el mártir". Aparte de resaltar la importancia del conflicto bélico en la fundación del país, el funcionario municipal apunta que Juan Rafael Mora se presenta como un signo de fortaleza y de carácter a la contemplación serena y justa de la historia, a la meditación de los hombres de estudio, al análisis de los maestros, a la admiración de sus conciudadanos y a la devoción cívica de la juventud de todos los tiempos; porque su figura ilustre es paradigma de la patria, salvada de los abismos de la opresión y del oprobio, gracias a la superior grandeza de su alma y a la clara visión de su pensamiento de estadista $y$ de conductor de pueblos (Lucha, 1956: 4). La posición de este periódico es interesante, pues en ningún momento señala el nombre de Juan Santamaría y su participación en la campaña nacional, posiblemente porque dudaba de su existencia.

Sin negar la visión de Mora en detectar los peligros, que para la soberanía del país implicaba la presencia de Walker en la región $y$ la necesidad de combatirlo, esto es solo una parte de su actuación como político. Debe señalarse que los políticos e intelectuales liberales de finales del siglo XIX comenzaron a mitificar la figura del prócer y a resaltar únicamente los aportes que su gobierno tuvo, no refieren que don Juan Rafael empañó la administración pública con hechos de corrupción y autoritarismo donde empleó el poder en beneficio propio (Molina, 2006: 9).

\section{CONCLUSIÓN}

El centenario de la Campaña Nacional fue utilizado por los gobernantes de turno para transmitir un discurso conciliador entre los intereses modernizantes, de integración centroamericana y la visión geopolítica de la Guerra Fría en Estados Unidos como unidad hemisférica. Además, se reforzaron los valores morales del arquetipo del campesino humilde y sencillo, con el fin de mantener a los grupos subalternos en la acriticidad $y$ pasividad.

Los artículos escritos en el Eco Católico tratan de dejar por sentada la existencia de Juan Santamaría, sin hacer un análisis valorativo de las fuentes a favor o en contra de este hecho. Por otra parte, se pretende ver en la figura de Santamaría una imagen donde los sectores subordinados se vieran representados, reproduciendo un discurso de conservación del orden establecido y de la jerarquía de clase.

La posición sobre la importancia del centenario de la lucha contra los filibusteros emitida en el periódico Lucha, en vez de rescatar la figura de Santamaría resalta la conducción y 
visión del expresidente Juan Rafael Mora, donde lo que se busca es su idealización y el sometimiento a una visión patriarcal de la historia nacional.

\section{BIBLIOGRAFIA}

\section{PERIÓDICOS}

Eco Católico. Año XXVI. Nro.15 (1297). Tomo 50. Abril 8 de 1956: 297-298.

La Nación. Año X. Nro. 2781. Martes 10 de abril de 1956: 12.

La Nación. Año X. Nro. 2783. Viernes 13 de abril de 1956: 3 .

Lucha. Edición Nro.5. 7 de julio de 1956: 4.

LIBROS

Díaz Arias, David. Historia del 11 de abril. Juan Santamaría entre el pasado y el presente (1915-2006). San José: Editorial de la Universidad de Costa Rica, 2006.

González Ortega, Alfonso. Mujeres y hombres de la posguerra costarricense (1950-1960). San José: Editorial de la Universidad de Costa Rica, 2005.

Hobsbawn, Eric y Ranger, Terence. La invención de la tradición. Barcelona: Crítica, 2002.

Meléndez Chaverri, Carlos. Santa Rosa. San José: Comisión Nacional de Conmemoraciones Históricas y Museo Histórico Juan Santamaría, 1979.

Meléndez Chaverri, Carlos. Juan Santamaría, una aproximación crítica y documental. Alajuela: Museo Histórico Cultural Juan Santamaría, 1982.

Meléndez Chaverri, Carlos. Juan Santamaría, el hombre y el héroe. Alajuela: Museo Histórico Cultural Juan Santamaría, 1983.

Méndez Alfaro, Rafael Ángel. Imágenes de poder: Juan Santamaría y el ascenso de la nación en Costa Rica (1860-1915). San José: EUNED, 2007.

Molina Jiménez, Iván. La Campaña Nacional (1856-1857). Una visión desde el siglo $X X I$. Edición del Museo Histórico-
Cultural Juan Santamaría. Alajuela, 2000.

Molina Jiménez, Iván (editor). Industriosa y sobria. Costa Rica en los días de la Campaña Nacional (1856-1857). South Woodstock, Vermont, Estados Unidos: Plumsock Mesoamerican Studies, 2007.

Molina Jiménez, Iván y Díaz Arias, David. La Campaña Nacional (1856-1857). historiografía, literatura y memoria. San José: EUCR, 2008.

Sanabria Martínez, Víctor. Los muertos en la Campaña Nacional de 1856-1857. San José: Imprenta Lehmann-Sauter \& Co., 1932.

Villena Fiengo, Sergio. Globalización. Siete ensayos heréticos sobre fútbol, identidad y cultura. San José: Ediciones Farben/ Grupo Editorial Norma, 2006.

REVISTAS

Comunicación. Vol.15. Nro.001. Cartago: Instituto Tecnológico de Costa Rica, enero-julio 2006.

Revista de Historia. Nro.25. Heredia: EUCR, 1992.

PUBLICACIONES EN INTERNET

Aguilar Piedra, Raúl. "La guerra centroamericana contra los filibusteros en 1856-1857: una aproximación a las fuentes bibliográficas y documentales". En: <http://www.latindex.ucr.ac.cr/ historia-51/10-Aguilar.pdf>

Díaz Arias, David Gustavo. "Comunidad política, identidades, ritos y rituales en la celebración del día de la independencia en Costa Rica, 1824-1921". Informe final del concurso: culturas e identidades en América Latina y el Caribe. Programa Regional de Becas CLACSO. 2001. En: $<$ http://bibliotecavirtual.clacso.org.ar/ar/ libros/becas/2000/diaz.pdf>

Escritos de José Figueres Ferrer. Política, economía y relaciones internacionales. Selección y edición Fundación pro Centro Cultural e Histórico José Figueres 
Ferrer. En: <http://www.editorialpln.

Fecha de ingreso: 20/09/2010 info/publicaciones/Escritos_de_Jose_

Fecha de aprobación: 31/03/2011

Figueres_Ferrer.pdf> 
